\title{
Changes in Bone Mineral Density, Body Composition, and Lipid Metabolism during Growth Hormone (GH) Treatment in Children with GH Deficiency*
}

\author{
ANNEMIEKE M. BOOT, MELANIE A. M. J. ENGELS, GEERT J. M. BOERMA, \\ ERIC P. KRENNING, AND SABINE M. P. F. DE MUINCK KEIZER-SCHRAMA \\ Department of Pediatrics, Division of Endocrinology (A.B., M.E., S.M.K.-S.) and Division of Clinical \\ Chemistry (G.B.), Sophia Children's Hospital, Department of Nuclear Medicine (E.P.), Dijkzigt \\ Hospital, Erasmus University, 3015 GJ Rotterdam, the Netherlands
}

\begin{abstract}
Adults with childhood onset GH deficiency (GHD) have reduced bone mass, increased fat mass, and disorders of lipid metabolism. The aim of the present study was to evaluate bone mineral density (BMD), bone metabolism, body composition, and lipid metabolism in GHD children before and during 2-3 yr of GH treatment (GHRx). Forty children with GHD, mean age $7.9 \mathrm{yr}$, participated in the study of bone metabolism and body composition; and an additional group of 17 GHD children, in the study of lipid metabolism. Lumbar spine BMD, total body BMD, and body composition were measured with dual-energy x-ray absorptiometry. Volumetric BMD (bone mineral apparent density, BMAD) was calculated to correct for bone size. BMD, BMAD, lean tissue mass, bone mineral content, fat mass, and percentage body fat were expressed as SD scores (SDS), in comparison with normative data of the same population. Lumbar spine BMD and BMAD and total body BMD were all decreased at baseline. All BMD variables increased
\end{abstract}

significantly during GHRx, lumbar spine BMD SDS, already after 6 months of treatment. Lean tissue mass SDS increased continuously. Bone mineral content SDS started to increase after 6 months GHRx Fat mass SDS decreased during the first 6 months of GHRx and remained stable thereafter. Biochemical parameters of bone formation and bone resorption did not differ from normal at baseline and increased during the first 6 months of GHRx. Serum 1,25 dihydroxyvitamin D increased continuously during GHRx, whereas PTH and serum calcium remained stable. Lipid profile was normal at baseline. Atherogenic index had decreased and apolipoprotein A1 (Apo-A1) had increased after 3 yr of treatment.

In conclusion, children with GHD have decreased bone mass. BMD, together with height and lean tissue mass, increased during GHRx. GHRx had a beneficial effect on lipid metabolism. (J Clin Endocrinol Metab 82: 2423-2428, 1997)

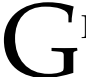
IS ESSENTIAL for normal growth during childhood and adolescence and influences bone mineralization and body composition in children and adults. In adults, GH is known to affect lipid metabolism. GH deficiency (GHD) of childhood onset in adults and GHD in children are associated with reduced bone mineral density (BMD) and lean tissue mass and increased fat mass (1-6). Studies in adults showed that these abnormalities change to normal after long-term treatment with human $\mathrm{GH}(1,7)$. Few reports showed that BMD improved in GHD children during GH therapy $(5,6)$. Bone mass accumulation during childhood determines the peak bone mass, which is a major determinant of osteoporosis later in life. Adults with GHD have an increased risk of cardiovascular disease because of disorders in lipid metabolism, which improve during GH therapy (GHRx) $(8,9)$. Reduction in triglycerides (TG) and low-density lipoprotein cholesterol (LDL) and increase of high-density lipoprotein cholesterol (HDL) have been observed in adults with GHD during therapy $(8-10)$. Reports of lipid metabolism during GHRx in children with GHD are contradictory (11-13).

Received February 27, 1997. Revised April 25, 1997. Accepted May 5, 1997

Address all correspondence and requests for reprints to: A. M. Boot, Sophia Children's Hospital, Division of Endocrinology, dr. Molewaterplein 60, 3015 GJ Rotterdam, the Netherlands. BV.
In the present study, lumbar spine and total body BMD lumbar spine BMD corrected for estimated bone volume, bone metabolism, body composition, and lipid metabolism were evaluated in GHD children before and during 2-3 yr of GHRx.

\section{Patients and Methods}

\section{Patients}

Forty children ( 24 boys and 16 girls) participated in the study. The mean age at the start of treatment was $7.9 \mathrm{yr}$ (range 0.4-16.9). In 2 children, younger than $4 \mathrm{yr}$, no BMD measurements were performed. In these young children, it is difficult to lie still to perform the measurement. One of them became $4 \mathrm{yr}$ old after $2 \mathrm{yr}$ of treatment, and then BMD measurements were performed.

All patients had decreased height velocity. The children had height SD scores (SDS) below 2, compared with Dutch reference values (14), except three patients. These children had a craniopharyngioma, low height velocity, and height SDS below -1 .

Eighteen children (14 boys and 4 girls, mean age $8.7 \mathrm{yr}$ ) had classic GHD, defined as 2 different $\mathrm{GH}$ provocation test peaks less than $5 \mu \mathrm{g} / \mathrm{L}$ and insulin-like growth factor (IGF)-1 and IGF-binding protein 3 (IGFBP3) below the mean of age- and sex-matched healthy controls (15). The other 22 patients ( 10 boys and 12 girls, mean age $7.4 \mathrm{yr}$ ) were categorized as nonclassic GHD. The diagnosis of 16 children was partial GHD defined as GH provocation peaks between 5-10 $\mu \mathrm{g} / \mathrm{L}$ and IGF-1 and IGF-BP3 below the mean, or GH provocation peaks between $10-15 \mu \mathrm{g} / \mathrm{L}$ and IGF1 and IGF-BP3 below 2 sD of normal. Five children formed a special group: 2 of them had GH provocation peaks more than $15 \mu \mathrm{g} / \mathrm{L}$ but IGF-1 and IGF-BP3 below 2 sD, and 2 had GH peaks between $10-15$ $\mu \mathrm{g} / \mathrm{L}$ and IGF-1 and IGF-BP3 that were 1.5 sD below normal. One girl had GH peaks between $10-15 \mu \mathrm{g} / \mathrm{L}$ but normal IGF-1. These 5 children 
had high IGF-1 response during a test after stimulation with GH. One girl with intrauterine growth retardation, without catch-up growth, had normal GH-peaks and IGF- 1 of -1 sD and a very low height SDS $(-4.6$ SD). Sixteen children had GHD of unknown origin. Eighteen had GHD of known origin: 8 had a malformation in the central nervous system, 2 had a syndrome with GHD (1 Prader-Willi and 1 Robinow), 7 had an intracerebral tumor (5 craniopharyngioma, 1 germinoma, and 1 astrocytoma), and 1 boy had received radiation therapy for a rhabdomyosarcoma of his left ear. Two children had Noonan syndrome, and 4 were born after intrauterine growth retardation.

Eight children had multiple pituitary hormone deficiencies and received hormonal replacement therapy. All patients had normal thyroid function before and during treatment.

Thirty-two patients were prepubertal (14 with classic and 18 with nonclassic GHD), 5 had Tanner stage 2 ( 2 with classic and 3 with nonclassic GHD), 2 had Tanner stage 3 ( 1 with classic and 1 with nonclassic GHD), and 1 had Tanner stage 4 (with classic GHD) (16). Three children (1 with classic and 2 with nonclassic GHD) entered puberty during the study period.

In the above mentioned children and 17 other children (10 boys and 7 girls, mean age $7.9 \mathrm{yr}$, sD 3.1), lipid metabolism was measured at baseline and during GH therapy. Of these 17 children, 6 patients had classic and 11 had nonclassic GHD. Eight had idiopathic GHD and 9 had GHD of known origin: 4 had a malformation in the central nervous system, 1 had an optic glioma, 1 had a pituitary microadenoma, 2 had hydrocephalus, and 1 had neurofibromatosis. The child with the optic glioma had multiple pituitary deficiencies. Fifteen were prepubertal, 1 had Tanner stage 1 , and 1 had Tanner stage 2. Lipid profile was evaluated at baseline in 55 children; after 1 yr, in 45 children; after 2 yr, in 33 children; and after 3 yr therapy, in 16 children.

All patients were treated with daily sc injections of biosynthetic human GH ( $2 \mathrm{IU} / \mathrm{m}^{2}$ body surface). The five children of the group of the IGF-1 response test received $3 \mathrm{IU} / \mathrm{m}^{2}$.

Informed consent was obtained from the parents of the patients.

\section{Methods}

Anthropometry, BMD and body composition measurements, and assessment of biochemical bone parameters were performed at baseline and 6 months, $1 \mathrm{yr}$, and $2 \mathrm{yr}$ after onset of GHRx. BMD and body composition measurements at 6 months missed in one patient. Height was measured with a Harpenden stadiometer. Height was compared with age- and sex-matched reference values (14) and expressed as (SDS). Body mass index was calculated as weight $/(\text { height })^{2}\left(\mathrm{~kg} / \mathrm{m}^{2}\right)$ and compared with age- and sex-matched reference values (17) and expressed as SDS.

BMD $\left(\mathrm{g} / \mathrm{cm}^{2}\right)$ of the lumbar spine and total body was measured by dual-energy $x$-ray absorptiometry (Lunar, DPXL/PED, Lunar Radiation Corporation, Madison, WI). The coefficient of variation has been reported as $1.04 \%$ for lumbar spine and $0.64 \%$ for total body (18). The coefficient of variation (SD) for lumbar spine was $1.1(0.2 \%)$ in our setting. The width of the vertebrae, measured by DXA, was used to calculate lumbar spine volumetric BMD, bone mineral apparent density $(B M A D)$, with the model BMAD $=$ BMD $\times[4 /(\pi \times$ width $)](19)$. BMD and BMAD results were compared with our age- and sex-matched Dutch reference values ( $\mathrm{n}=500,4-20 \mathrm{yr}$ old) (20) and expressed as SDS. With the total body measurement by DXA, the body composition was measured as lean tissue mass (g), fat mass (g), and bone mineral content (g). Total tissue mass is the sum of these three variables. Percentage body fat is given for total tissue mass. The coefficients of variation have been reported as $2.2 \%$ for fat mass, $1.1 \%$ for lean tissue mass, and $0.6 \%$ for bone mineral content (18). Bone mineral content, lean tissue mass, fat mass, and percentage body fat were compared with our age- and sexmatched Dutch reference values (4-20 yr old) and expressed as SDS (21).

Bone age was assessed yearly by one investigator (M. Engels), using an $\mathrm{x}$-ray of the left hand, according to the Tanner-Whitehouse radiusulna-short bones method (22).

Blood samples were taken in the morning for the assessment of calcium, phosphate, alkaline phosphatase, 1,25 dihydroxyvitamin D, PTH, osteocalcin, the carboxyterminal propeptide of type I collagen (PICP), cross-linked telopeptide of collagen I (ICTP), and IGF-1. Osteocalcin and intact PTH were measured by RIA (Incstar Corporation, Stillwater, MN); 1,25 dihydroxyvitamin D by RIA by Immuno Diagnostic Systems (Boldon, UK). PICP and ICTP was measured with an RIA kit (Orion Diagnostica, Espoo, Finland) with coefficients of variation of $4-6 \%$ and $4-8 \%$, respectively. Our own reference values for osteocalcin, PICP, and ICTP (respectively $n=25, n=82$, and $n=88$ ) were used for prepubertal children. Reference values for the older children were derived from other studies that used the same assays (23-25). For measurements of IGF-1 (nmol/L), kits from Med-Genix Diagnostics, Fleurus, Belgium, were used. IGF-1 sex- and age-matched reference values were based on 600 samples of a healthy Dutch population (15). In the first morning, void of urine, the ratio of hydroxyproline and creatinine $(\mathrm{OHP} /$ creat) and the ratio of calcium and creatinine (CA/creat) were evaluated.

Fasting blood samples were obtained yearly for the assessment of TG, total cholesterol (TC), HDL, LDL, very low-density lipoprotein cholesterol (VLDL), free fatty acids (FFA), Apo-A1, and apolipoprotein B (Apo-B). Atherogenic index was calculated as the ratio of TC to HDL.

TC, TG, Apo-A1, and Apo-B were measured on DuPont de Nemours Dimension analyzer with reagents as provided by the manufacturer (26). TC is liberated from all lipoprotein particles by detergents; the esterified fraction (about $70 \%$ of TC) is hydrolyzed by the action of cholesterol esterase. TC is then oxidized by cholesterol oxidase, which generates 1 mol hydrogen peroxide for each mole of cholesterol. The peroxide generates a chromophore, which is measured photometrically by a triplewavelength endpoint technique. The assay is calibrated by human serum samples with reference method-based set points and is directly comparable with the standard method of Abell-Kendall (27). TG are converted to free glycerol by lipase, and the glycerol is oxidized (by glycerol dehydrogenase) to dihydroxy-acetone under formation of $\mathrm{NADH}$, which is measured using a kinetic, bichromatic method. Preexisting glycerol (usually below $0.1 \mathrm{mmol} / \mathrm{L}$ ) is included in the result (28).

HDL is analyzed after Apo-B, containing lipoprotein particles, has been precipitated from the serum by heparin-MnCl2 solution (29). LDL is calculated by the following Friedewald formula: $\mathrm{LDL}=\mathrm{TC}-(\mathrm{HDL}$ + VLDL), where VLDL $=$ TG and ${ }^{*}=0.45 \mathrm{mmol} / \mathrm{L}(30)$.

Apo-B in the assay reacts with polyclonal antibodies against human Apo-B to form an immunoprecipitate; the reaction is enhanced by adding polyethyleneglycol. The endpoint turbidity is measured by photometry in a bichromatic procedure (31). Apo-A1 is measured with polyclonal antibodies against human Apo-A1 (31). This reaction also is accelerated with polyethyleneglycol. FFA are measured by specific enzymatic esterification to Acyl-CoA and a follow-up reaction with acyl$\mathrm{CoA}$-oxidase to generate hydrogen peroxide. This hydrogen peroxide is then measured after color formation with a chromogen (32). Ascorbate oxidase eliminates vitamin C interference. Dutch age-matched reference values were used for TC and HDL (33). For the other lipids our own reference values of 59 healthy children between 2-10 yr and available reference data (34) were used.

\section{Statistical analysis}

One-sample $t$ tests were performed to compare the mean SDS values with normal. Two-sample $t$ tests were used to compare variables with a normal distribution between two groups. We tested if the average within patient change differed from zero with one-sample $t$ test. Pearson correlation coefficient was calculated to test the association between two variables with a normal distribution. Spearman's rank correlation coefficient was used, in case of a nonnormal distribution.

\section{Results}

Table 1 shows the results of lumbar spine BMD and BMAD SDS, total body BMD SDS, height SDS, body mass index SDS, and body composition variables at baseline and during GHRx. At baseline, lumbar spine BMD and BMAD SDS and total body BMD SDS were significantly lower than normal $(P<0.001$ for lumbar spine and total body BMD SDS and $P<$ 0.02 for BMAD SDS). Lumbar spine BMD and BMAD SDS and total body BMD SDS were below -2 in 11, 3, and 5 patients, respectively. The results of boys did not differ significantly from these of girls. Lumbar spine BMD SDS increased already after 6 months GHRx, lumbar spine BMAD 
TABLE 1. Mean (SD) of different variables at baseline and during GHRx

\begin{tabular}{lcccc}
\hline & Baseline & $\begin{array}{c}6 \text { Months } \\
\text { GHRx }\end{array}$ & 1 yr GHRx & 2 yr GHRx \\
\hline & $\mathrm{n}=38$ & $\mathrm{n}=37$ & $\mathrm{n}=33$ & $\mathrm{n}=33$ \\
Lumbar spine BMD SDS & $-1.62(1.22)$ & $-1.33(1.17)^{a}$ & $-0.98(1.11)^{a}$ & $-0.64(0.87)^{a}$ \\
Lumbar spine BMAD SDS & $-0.51(1.21)$ & $-0.50(1.17)$ & $-0.37(1.06)$ & $-0.19(1.00)^{a}$ \\
Total body BMD SDS & $-0.94(1.20)$ & $-1.35(1.20)^{b}$ & $-1.02(1.2)$ & $-0.61(1.16)^{b}$ \\
Bone mineral content SDS & $-2.29(1.11)$ & $-2.36(1.56)$ & $-1.52(1.29)^{a}$ & $-1.24(0.99)^{a}$ \\
Lean tissue mass SDS & $-2.72(0.83)$ & $-1.86(0.87)^{a}$ & $-1.53(0.79)^{a}$ & $-1.14(0.54)^{a}$ \\
Fat mass SDS & $-0.02(1.76)$ & $-0.59(1.80)^{c}$ & $-0.31(2.00)^{c}$ & $-0.59(1.63)$ \\
\% Body fat SDS & $0.93(2.11)$ & $-0.39(1.99)^{a}$ & $-0.10(2.04)^{a}$ & $-0.45(1.66)^{c}$ \\
Height SDS & $-2.98(0.76)$ & $-2.32(0.84)^{a}$ & $-1.86(0.91)^{a}$ & $-1.63(0.80)^{a}$ \\
BMI SDS & $0.45(2.40)$ & $0.24(2.29)$ & $0.39(2.42)$ & $0.37(2.02)$ \\
\hline
\end{tabular}

The mean within patient change from baseline was tested.

${ }^{a} P<0.001 ;{ }^{b} P<0.02 ;{ }^{c} P<0.01$ compared to baseline.

SDS after 2 yr GHRx (Table 1). Total body BMD SDS decreased initially after 6 months GHRx and increased thereafter (Table 1). The observed changes remained if pubertal children were excluded. Mean lumbar spine and total body BMD SDS were still significantly lower than zero after $2 \mathrm{yr}$ $\operatorname{GHRx}(P<0.01$ for lumbar spine and $P<0.02$ for total body); mean spine BMAD SDS did not differ significantly from zero. None of the patients had lumbar spine BMD or BMAD SDS below -2 after $2 \mathrm{yr}$ of treatment. Total body BMD SDS of 4 patients was below -2 at that time, 3 of them also had a low value at baseline. At baseline mean bone mineral content and lean tissue mass SDS were decreased $(P<0.001)$ and percentage body fat increased $(P<0.02)$. Bone mineral content SDS started to increase after 6 months GHRx. Lean tissue mass SDS and height SDS increased continuously during GHRx. Fat mass SDS and percentage body fat SDS decreased after 6 months GHRx and remained stable thereafter. After 2 yr GHRx mean bone mineral content and lean tissue mass SDS were still significantly lower than normal (both $P<$ 0.001); mean fat mass SDS and percentage body fat SDS did not differ significantly from normal. The BMD variables, bone mineral content SDS, and lean tissue mass SDS did not differ significantly between patients with classic GHD and those with nonclassic GHD. Fat mass and percentage fat SDS were significantly higher in patients with classic GHD, compared with the other patients (both $P<0.001$ ). The changes in lumbar spine BMD SDS, BMAD SDS, total body BMD SDS, and body composition variables during GHRx were not sig- nificantly different between the classic and nonclassic GHD patients.

When BMD SDS was calculated for bone age $\left(\operatorname{SDS}_{\mathrm{BA}}\right)$, mean lumbar spine $\mathrm{BMD} \mathrm{SDS}_{\mathrm{BA}}$ at baseline was significantly decreased (mean -0.88 , sD 1.11, $P<0.001$ ). Mean lumbar spine BMAD SDS ${ }_{\mathrm{BA}}$ and total body BMDSDS $\mathrm{BA}_{\mathrm{BA}}$ did not differ from normal. Because bone age was below $4 \mathrm{yr}$ in 12 children, no SDS $_{\mathrm{BA}}$ could be calculated, because we had no reference values of that age. During GH therapy, lumbar spine BMD $\mathrm{SDS}_{\mathrm{BA}}$ increased significantly; after $1 \mathrm{yr}$, the mean increase was 0.34 (sD $0.12, P<0.01$ ); from 1 to $2 \mathrm{yr}, 0.30$ (sD $0.42, P<$ 0.01 ). After 2 yr GHRx, mean lumbar spine $\operatorname{SDS}_{\mathrm{BA}}$ was -0.54 (sD 0.79), significantly lower than zero $(P<0.02)$. Total body BMD SDS $_{\mathrm{BA}}$ decreased after 1 yr (mean -0.45 (sD 0.70), $P<$ 0.01 ) and increased during the 2 nd year (mean 0.41 (sD 0.70 ),

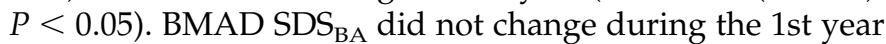
and increased during the 2nd year (mean 0.22 (SD 0.35), $P<$ 0.02).

Table 2 shows the biochemical results at baseline and during GHRx. Mean osteocalcin, PICP, and ICTP did not differ from normal at baseline. After 6 months GHRx, osteocalcin, PICP, ICTP, alkaline phosphatase, 1,25 dihydroxyvitamin D, IGF-1, and OHP/creat had increased significantly. Osteocalcin and ICTP remained stable thereafter; $\mathrm{PICP}$, alkaline phosphatase, phosphate, and $\mathrm{OHP} /$ creat decreased significantly; 1,25 dihydroxyvitamin D and IGF-1 continued to increase. PTH and CA/creat did not change

TABLE 2. Mean (SD) of biochemical parameters at baseline and during GHRx in GHD children

\begin{tabular}{|c|c|c|c|c|}
\hline & Baseline & $\begin{array}{l}6 \text { Months } \\
\text { GHRx }\end{array}$ & 1 yr GHRx & 2 yr GHRx \\
\hline & $\mathrm{n}=39$ & $\mathrm{n}=38$ & $\mathrm{n}=33$ & $\mathrm{n}=21$ \\
\hline Osteocalcin $(\mu \mathrm{g} / \mathrm{L})$ & $13.3(4.7)$ & $20.8(8.1)^{a}$ & $20.7(5.5)^{a}$ & $16.7(4.2)$ \\
\hline $\operatorname{PICP}(\mu \mathrm{g} / \mathrm{L})$ & $372(240)$ & $582(262)^{a}$ & $458(152)$ & 355 (149) \\
\hline ICTP $(\mu \mathrm{g} / \mathrm{L})$ & $12.9(4.6)$ & $17.4(5.6)^{a}$ & $18.1(4.3)^{a}$ & $16.8(5.6)$ \\
\hline Alkaline phosph. (U/L) & $174.4(51.7)$ & $245.7(82.0)^{a}$ & $255.6(93.4)^{a}$ & $226.0(87.9)^{b}$ \\
\hline PTH (ng/L) & $18.9(7.4)$ & $21.0(7.5)$ & $24.4(9.2)$ & $24.1(11.3)$ \\
\hline $1,25 \mathrm{OH}$ vit. $\mathrm{D}(\mathrm{pmol} / \mathrm{L})$ & $96.2(25.8)$ & $130.0(49.3)^{a}$ & $141.4(46.5)^{a}$ & $158.9(41.1)^{a}$ \\
\hline IGF-1 (nmol/L) & $17.0(24.4)$ & $34.7(25.4)^{a}$ & $41.5(29.3)^{a}$ & $45.2(31.1)^{a}$ \\
\hline Calcium (mmol/L) & $2.45(0.09)$ & $2.45(0.09)$ & $2.44(0.08)$ & $2.44(0.08)$ \\
\hline Phosphate (mmol/L) & $1.41(0.17)$ & $1.70(0.21)^{a}$ & $1.63(0.18)^{a}$ & $1.49(0.15)^{b}$ \\
\hline Urine OHP/creat (mg/g) & $105(77)$ & $133(47)^{c}$ & $151(55)^{c}$ & $118(43)$ \\
\hline Urine $\mathrm{Ca} /$ creat & $0.45(0.46)$ & $0.46(0.44)$ & $0.32(0.25)$ & $0.39(0.34)$ \\
\hline
\end{tabular}

Alkaline phosph., alkaline phosphatase; $1,25 \mathrm{OH}$ vit. D, 1,25 dihydroxyvitamin $\mathrm{D}$; The mean within patient change from baseline was tested.

${ }^{a} P<0.001 ;{ }^{b} P<0.02 ;{ }^{c} P<0.01$ compared to baseline. 
during GHRx. The results were not different when pubertal children were excluded.

Table 3 shows the results of lipid metabolism at baseline and during GHRx. At baseline, the mean levels of the lipid profile were normal. One child had TC above $6 \mathrm{mmol} / \mathrm{L}$, and three children had TG above $1.7 \mathrm{mmol} / \mathrm{L}$. All patients had normal TC and TG after 3 yr GHRx. Only Apo-A1 and atherogenic index changed significantly during GHRx; Apo-A1 had increased and atherogenic index had decreased after 3 yr of GHRx.

At baseline, height SDS correlated with lumbar spine BMD and BMAD SDS $(r=0.43, P<0.01$; and $r=0.36, P<0.05$, respectively) and not with total body BMD SDS. Body mass index SDS related to all three BMD variables $(\mathrm{r}=0.51, P<$ 0.01 for lumbar spine BMD SDS; $\mathrm{r}=0.52, P<0.001$ for lumbar spine BMAD SDS; and $r=0.44, P<0.01$ for total body BMD SDS). Biochemical bone parameters and IGF-1 SDS did not relate to lumbar spine BMD, BMAD SDS, total body BMD SDS, or height SDS. IGF-1 SDS correlated with lean tissue mass SDS $(r=0.35, P<0.05)$ and not with bone mineral content, fat mass, or percentage body fat SDS. Height SDS correlated with bone mineral content SDS and lean tissue mass SDS $(\mathrm{r}=0.69, \mathrm{r}=0.62$, respectively; both $P<$ $0.001)$. The different lipids did not relate to fat mass or percentage body fat SDS or IGF-1 SDS.

The change $(\Delta)$ in height SDS between baseline and $2 \mathrm{yr}$ GHRx did not relate to $\Delta$ in lumbar spine BMD or BMAD SDS or total body BMD SDS during the same period. $\Delta$ in height SDS related to $\Delta$ in bone mineral content SDS ( $\mathrm{r}=0.41, P<$ 0.02 after $1 \mathrm{yr}$; and $\mathrm{r}=0.44, P<0.05$ after 2 yr GHRx). Only after 6 months GHRx, $\Delta$ in 1,25 dihydroxyvitamin D had a significant correlation with $\Delta$ lumbar spine BMD and BMAD SDS ( $\mathrm{r}=0.34, P<0.05$; and $\mathrm{r}=0.57, P<0.001$, respectively) and not with $\Delta$ in total body BMD or bone mineral content SDS. Changes of the other biochemical bone parameters had no significant relation with $\Delta$ in lumbar spine BMD or BMAD SDS or total body BMD or bone mineral content SDS. Only $\Delta$ in ICTP, after 6 months, correlated with $\Delta$ in height SDS during the same period ( $\mathrm{r}=0.48, P<0.01$ for all children; $\mathrm{r}=0.40, P<0.05$ only for prepubertal children). $\Delta$ in IGF-1 SDS, after 6 months or after $2 \mathrm{yr}$, did not relate to $\Delta$ height SDS. $\Delta$ in 1,25 dihydroxyvitamin $\mathrm{D}$ between baseline and 2 yr GHRx related to $\Delta$ in IGF-1 SDS $(\mathrm{r}=0.52, P<0.05) . \Delta$ in IGF-1 SDS, after 6 months, correlated with $\Delta$ in lean tissue mass SDS $(r=0.45, P<0.02) . \Delta$ in IGF-1 SDS, between baseline and $2 \mathrm{yr}$, correlated negatively with $\Delta$ percentage body fat $(\mathrm{r}=-0.54, P<0.05) . \Delta$ in IGF-1 SDS did not relate to $\Delta$ in any lipids or atherogenic index. After 2 yr of treatment, IGF-1 SDS related to lean tissue mass SDS $(r=0.52, P<$ 0.05 ) and not to the BMD variables or bone mineral content SDS.

\section{Discussion}

During GHRx, lumbar spine BMD and BMAD, and total body BMD, together with height and lean tissue mass, increased significantly in children with GHD. Biochemical parameters of bone formation and bone resorption increased, indicating an enhanced bone turnover. $\mathrm{GH}$ has both direct and indirect actions on bone. In animal models, GH stimulates osteoblast number and function and the production of various bone matrix factors (35). Paracrine activity of osteoblasts stimulates osteoclasts. Bone formation is enhanced preferentially to bone resorption during $\mathrm{GH}$ administration (35). As in other tissues, part of the effects of GH are mediated through IGF-1. In childhood, GH affects both linear bone growth and the accumulation of BMD. In GHD children, both are decreased, as shown by low height SDS and BMD SDS. Some studies found a decreased osteocalcin and PICP $(36,37)$ in GHD children; others did not find a difference with normals $(38,39)$. The wide range in normal values may be the reason that osteocalcin and PICP were in the normal range in the present study. Osteocalcin and PICP are related to linear growth velocity $(36,39,40)$. Increased values of all markers are found during periods of high growth velocity, such as the first years of life and puberty in healthy children (40). During GHRx, the increase of both formation and resorption markers reflects growth, modeling, and remodeling of bone tissue. The increased bone turnover resulted in an improvement of BMD.

GH increases muscle mass, in agreement with our finding of an increase in lean tissue mass, and strength (35). This may be associated with increased physical activity, which may have a positive effect on BMD.

Lumbar spine BMD of adults with GHD decreases initially after 3-6 months GHRx and starts to increase after more than 1 yr of treatment $(1,7)$. In the present study, lumbar spine BMD had increased and total body BMD decreased after 6 months treatment. BMD is an areal density and does not adjust for bone size completely. Total body bone mineral

TABLE 3. Change in lipid profile during GH treatment (GHRx), mean (SD)

\begin{tabular}{|c|c|c|c|c|c|c|c|c|c|}
\hline & Baseline & & $\begin{array}{c}1 \mathrm{yr} \\
\text { GHRx }\end{array}$ & & $\begin{array}{c}2 \mathrm{yr} \\
\text { GHRx }\end{array}$ & & $\begin{array}{c}3 \mathrm{yr} \\
\text { GHRx }\end{array}$ & & $\begin{array}{c}\text { Reference } \\
\text { values }\end{array}$ \\
\hline & $\mathrm{n}$ & & $\mathrm{n}$ & & $\mathrm{n}$ & & $\mathrm{n}$ & & \\
\hline Total cholesterol (mmol/L) & 55 & $4.41(0.93)$ & 45 & $4.30(1.26)$ & 33 & $4.17(0.82)$ & 16 & $3.96(0.85)$ & $3.2-6.0$ \\
\hline Triglycerides (mmol/L) & 55 & $0.98(0.44)$ & 45 & $1.02(0.41)$ & 33 & $0.98(0.34)$ & 16 & $0.88(0.23)$ & $0.2-1.7$ \\
\hline $\mathrm{LDL}(\mathrm{mmol} / \mathrm{L})$ & 54 & $2.75(0.87)$ & 43 & $2.63(1.12)$ & 29 & $2.44(0.61)$ & 14 & $2.46(0.61)$ & $1.3-3.7$ \\
\hline HDL (mmol/L) & 55 & $1.21(0.28)$ & 44 & $1.17(0.29)$ & 33 & $1.26(0.30)$ & 16 & $1.27(0.27)$ & $0.9-1.6$ \\
\hline VLDL (mmol/L) & 53 & $0.44(0.20)$ & 43 & $0.48(0.20)$ & 24 & $0.45(0.14)$ & 13 & $0.40(0.09)$ & $0.1-0.8$ \\
\hline Free fatty acids $(\mathrm{mmol} / \mathrm{L})$ & 50 & $0.86(0.47)$ & 45 & $0.73(0.32)$ & 31 & $0.65(0.25)$ & 15 & $0.61(0.23)$ & $0.2-1.3$ \\
\hline Apo-A1 (g/L) & 54 & $1.35(0.20)$ & 44 & $1.30(0.18)$ & 30 & $1.39(0.22)$ & 16 & $1.40(0.16)^{\mathrm{a}}$ & $0.8-1.5$ \\
\hline Apo-B (g/L) & 54 & $0.85(0.22)$ & 44 & $0.83(0.29)$ & 30 & $0.83(0.15)$ & 16 & $0.76(0.17)$ & $0.6-1.1$ \\
\hline Atherogenic index & 55 & $3.85(1.25)$ & 44 & $3.79(1.53)$ & 33 & $3.41(0.76)$ & 16 & $3.20(0.72)^{b}$ & \\
\hline
\end{tabular}

Atherogenic index $=$ total cholesterol to HDL ratio. The mean within patient change from baseline was tested.

${ }^{a} P<0.05 ;{ }^{b} P<0.02$ compared to baseline. 
content remained stable during the first 6 months, so the initial decrease in total body BMD reflects a faster rate of bone expansion than mineral acquisition. Bone turnover in trabecular bone, present in lumbar spine, is higher than in cortical bone, $80 \%$ of the total skeleton (41). This may explain why lumbar spine BMD starts to increase earlier than total body BMD. During GHRx, patients had an increase of height SDS. After 2 yr of treatment, BMAD (corrected for estimated bone volume) had increased, as well, so one may conclude that finally, true bone density improved during GHRx.

The changes in body composition found in the present study are in agreement with known lipolytic and anabolic effects of GH. GHRx had a short-term lipolytic effect during the first 6 months of treatment, while the anabolic effect continued. Similar results have been reported in other studies in adults and children with GHD and short stature children during GHRx (1, 42-44).

GH administration had a stimulatory effect on serum 1,25 dihydroxyvitamin D, whereas serum calcium and PTH remained unchanged. More studies found an increase in 1,25 dihydroxyvitamin D in adults (2), as well as in children (4). Renal $1 \alpha$ hydroxylase activity is enhanced through IGF-1 (45), which agrees with the correlation we observed between $\Delta$ in IGF-1 SDS and $\Delta$ in 1,25 dihydroxyvitamin D. The synthesis of osteocalcin is induced by the action of 1,25 dihydroxyvitamin D (46). Administration of 1,25 dihydroxyvitamin D to GHD children increased serum osteocalcin levels (47). Part of the stimulatory action on osteoblastic activity of GH might be mediated by 1,25 dihydroxyvitamin $\mathrm{D}$. This is supported by our finding of a correlation between the increase of 1,25 dihydroxyvitamin $\mathrm{D}$ and the increase in BMD.

In contrast to adults with GHD, the children in the present study had normal mean values of lipids at baseline. The difference in lipid profile between GHD adults and children may reflect the population trend for a rise in cholesterol and LDL with increasing age (48). Studies in adults reported a decrease in TC, LDL, and apo B after 2-12 months GH administration $(8,9,49)$ and an increase of HDL (10). The reported effects of GHD on serum lipids in children with GHD are inconsistent between studies. Some studies showed no changes in TC and HDL during 6-12 months of GHRx (12), whereas others found a decrease in TC (13) or an increase in HDL (11). In the present study, the atherogenic index decreased, in agreement with a study of Kohno et al. (11) in prepubertal boys during 9 months of GH therapy. In a study evaluating the efficacy of lipid profiles, the atherogenic index was the most efficient predictor of coronary heart disease in adults (50). In healthy children, no age-related change in TC was observed between 5 and $10 \mathrm{yr}$ of age, but TC decreased between 10 and 16 yr in boys, as well as in girls (33). Mean HDL decreased slightly in boys and girls until the age of 17 (33). Therefore, the decrease in atherogenic index in the present study may be age-related. However, Apo-A1, the major apolipoprotein of HDL, increased also, so it seems that GHRx has a beneficial effect on lipid metabolism in children with GHD.

In conclusion, children with GHD had low BMD. After 2 yr of GHRx, lumbar spine BMD of all patients was within normal limits. Eighty-one percent of the patients had normal total body BMD at that time. The positive influence of GH on
BMD might be mediated partly by the increase of 1,25 dihydroxyvitamin D. Fat mass decreased and lean tissue mass increased during treatment. In contrast to adults, children with GHD had a normal lipid profile. Atherogenic index improved during GHRx.

\section{Acknowledgments}

The authors thank Jopie Hensen, of the Department of Nuclear Medicine, for her assistance in DXA measurements; Manon van Paasen, Sophie Dumas, and Ingrid Beukers, of the Out-Patient Department; and Marianne van Fessem, of the Clinical Chemistry Laboratory.

\section{References}

1. Degerblad M, Elgingy N, Hall K, Sjöberg HE, Thoren M. 1992 Potent effect of recombinant growth hormone on bone mineral density and body composition in adults with panhypopituitarism. Acta Endocrinol (Copenh). 126:387-393.

2. Binnerts A, Swart GR, Wilson JHP, et al. 1992 The effect of GH administration in GH deficient adults on bone, protein, carbohydrate and lipid homeostasis, as well as on body composition. Clin Endocrinol (Oxf). 37:79-87.

3. Shore RM, Chesney RW, Mazess RB, Rose PG, Bargman GJ. 1980 Bone mineral status in growth hormone deficiency. J Pediatr. 96:393-396.

4. Saggese G, Baroncelli GI, Bertelloni S, Cinquanta L, DiNero G. 1993 Effects of long-term treatment with growth hormone on bone and mineral metabolism in children with growth hormone deficiency. J Pediatr. 122:37-45.

5. Zamboni G, Antoniazzi F, Radetti G, Musumeci C, Tato L. 1991 Effects of two different regimens of recombinant human growth hormone therapy on the bone mineral density of patients with growth hormone deficiency. J Pediatr. 119:483-485.

6. Saggese G, Baroncelli GI, Bertelloni S, Barsanti S. 1996 The effect of longterm growth hormone treatment on bone mineral density in children with $\mathrm{GH}$ deficiency in the attainment of peak bone mass. J Clin Endocrinol Metab. 81:3077-3083

7. Vandeweghe M, Taelman P, Kaufman JM. 1993 Short and long-term effects of growth hormone treatment on bone turnover and bone mineral content in adult growth hormone-deficient males. Clin Endocrinol (Oxf). 39:409-415.

8. Garry P, Collins P, Devlin JG. 1996 An open 36-month study of lipid changes with growth hormone in adults: lipid changes following replacement of growth hormone in adult acquired growth hormone deficiency. Eur J Endocrinol. 134:61-66.

9. Russel-Jones DL, Walts GF, Weissberger A, et al. 1994 The effect of growth hormone replacement on serum lipids, lipoproteins, apolipoproteins and cholesterol precursors in adult growth hormone deficient patients. Clin Endocrinol (Oxf). 41:345-350.

10. Johansson G, Oscarsson J, Rosen T, et al. 1995 Effects of 1 year of growth hormone therapy on serum lipoprotein levels in growth hormone deficient adults. Arterioscler Thromb Vasc Biol. 15:2142-2150.

11. Kohno H, Ueyama N, Yanai S, Ukaji K, Honda S. 1994 Beneficial effect of growth hormone on atherogenic risk in children with growth hormone deficiency. J Pediatr. 126:953-955.

12. Schaefer GB, Greger NG, Fesmire JD, Blackett PR, Wilson DP, Frindik JP. 1994 Lipids and apolipoproteins in growth hormone deficient children during treatment. Metabolism. 43:1457-1461.

13. De Muinck Keizer-Schrama S, Rikken B, Hokken-Koelega A, Wit JM. 1994 Comparative study of two doses of growth hormone for growth hormone deficiency. Arch Dis Child. 71:12-18.

14. Roede MJ, van Wieringen JC. 1985 Growth diagrams 1980, Netherlands. Third nationwide survey. T Soc Gezondheidszorg. 63(S):1-34.

15. Hokken-Koelega ACS, Hackeng WHL, Stijnen T, Wit JM, de Muinck Keizer SMPF, Drop SLS. 1990 Twenty-four hour plasma growth hormone profiles, urinary GH excretion and plasma insulin-like growth factor-I and -II levels in prepubertal children with chronic renal insufficiency and severe growth retardation. J Clin Endocrinol Metab. 71:688-695.

16. Tanner JM, Whitehouse R. 1976 Longitudinal standards for height, weightheight, weight-velocity and stages of puberty. Arch Dis Child. 51:170-179.

17. Weststrate JA, Deurenberg P, Van Tinteren H. 1989 Body fat distribution and adiposity indices in Dutch children 0-18 year age. Int J Obes. 13:465-477.

18. Johnson J, Dawson Hughes B. 1991 Precision and stability of dual energy x-ray absorptiometry measurements. Calcif Tissue Int. 49:174-178.

19. Kröger H, Vainio P, Nieminen J, Kotamieni A. 1995 Comparison of different models for interpreting bone mineral density measurements using DXA and MRI technology. Bone. 17:157-159.

20. Boot AM, de Ridder MAJ, Pols HAP, Krenning EP, de Muinck KeizerSchrama SMPF. 1997 Bone mineral density in children and adolescents: relation to puberty, calcium intake and physical activity. J Clin Endocrinol Metab. 82:57-62.

21. Boot AM, Bouquet J, de Ridder MAJ, Krenning EP, de Muinck Keizer- 
Schrama SMPF. 1997 Determinants of body composition, measured by dual energy x-ray absorptiometry, in Dutch children and adolescents. Am J Clin Nutr. In press.

22. Tanner JM, Whitehouse RH, Cameron N, Marshall WA, Healy MJR, Goldstein H. 1983 Assessment of skeletal maturity and prediction of adult height (TW2 method). 2nd ed. London: Academic Press.

23. Kruse K, Kracht U. 1986 Evaluation of serum osteocalcin as an index of altered bone metabolism. Eur J Pediatr. 145:27-33.

24. Bluhmsohn A, Hannon RA, Wrate R, et al. 1994 Biochemical markers of bone turnover in girls during puberty. Clin Endocrinol (Oxf). 40:663-670.

25. Hertel NT, Stoltenberg M, Juul A, et al. 1993 Serum concentrations of Type I and III procollagen propeptides in healthy children and girls with central precocious puberty during treatment with gonadotropin-releasing hormone analog and cyproterone acetate. J Clin Endocrinol Metab. 76:924-927.

26. Knight D, Singer D, White JM, Fraser CG. 1988 Laboratory evaluation of the Du Pont "Dimension Clinical Chemistry System". Clin Chem. 34:1899-1903.

27. Boerma GJM, Jansen AP, Jansen RTP, Leijnse B, Van Strik R. 1996 Minimizing interlaboratory variation in routine assays of serum cholesterol by the use of serum calibrators. Clin Chem. 32:943-947.

28. Tiffany TO, Morton JM, Hall EM, Garrett AD. 1974 Clinical evaluation of kinetic enzymatic, fixed time and integral analysis of serum triglycerides. Clin Chem. 20:476

29. Boerma GJM. 1987 Standardization of serum cholesterol and HDL-cholesterol measurements in the Netherlands: an overview. Tijdschr NVKC. 12:163-167.

30. Friedewald WT, Levy RI, Fredrickson DS. 1972 Estimation of the concentration of low density lipoprotein cholesterol in plasma, without the use of preparative ultracentrifuge. Clin Chem. 18:499-502.

31. Boerma GJM, De Bruijn AM, Van Teunenbroek A. 1994 Reference values for apolipoprotein A-1 and apolipoprotein B in serum depend on choice of assay techniques. Eur J Clin Chem Clin Biochem. 32:923-927.

32. Jeevanandam M, Hsu YC, Ramias L, Schiller WR. 1989 A rapid automated micromethod for measuring free fatty acids in plasma/serum. Clin Chem. 35:2228-2231.

33. Stiphout van WAHJ, Hofman A, Bruijn de AM, Valkenburg HA. 1985 Distributions and determinants of total and high-density lipoprotein cholesterol in Dutch children and young adults. Prev Med. 14:169-180.

34. Tietz NW. 1995 Clinical guide to laboratory tests. 3rd ed. Philadelphia: WB Saunders; ISBN 0-7216-5035-x.

35. Inzucchi SE, Robbins RJ. 1994 Effects of growth hormone on human bone biology. J Clin Endocrinol Metab. 79:691-694.

36. Saggese G, Baroncelli GI, Bertelloni S, Cinquanta L, DiNero G. 1994 Twentyfour-hour osteocalcin, carboxyterminal propeptide of type I procollagen, and aminoterminal propeptide of type III procollagen rhythms in normal children and growth retarded children. Pediatr Res. 35:409-415.
37. Johansen JS, Jensen SB, Riis BJ, Rasmussen L, Zachman M, Christiansen C. 1990 Serum bone gla protein: a potential marker of growth hormone deficiency and the response to GH therapy. J Clin Endocrinol Metab. 71:122-126.

38. Kanzaki S, Hosoda K, Moriwake T, et al. 1992 Serum propeptide and intact molecular osteocalcin in normal children and children with growth hormone deficiency: a potential marker of bone growth and response to $\mathrm{GH}$ therapy. J Clin Endocrinol Metab. 75:1104-1109.

39. Trivedi P, Risteli J, Risteli L, Hindmarsh PC, Brook CGD, Mowat AP. 1991 Serum concentrations of the type I and III procollagen propeptides as biochemical markers of growth velocity in healthy infants and children and in children with growth disorders. Pediatr Res. 30:276-280.

40. Calvo MS, Eyre DR, Gundberg CM. 1996 Molecular basis and clinical application of biological markers of bone turnover. Endocr Rev. 17:333-368.

41. Dempster DW, Lindsay R. 1993 Pathogenesis of osteoporosis. Lancet. 341:797-805.

42. Ogle GD, Rosenberg AR, Calligeros D, Kainer G. 1994 Effects of growth hormone treatment for short stature on calcium homeostasis, bone mineralisation, and body composition. Horm Res. 41:16-20.

43. Vaisman N, Zadik Z, Shamai Y, Franklin L, Dukhan R. 1992 Changes in body composition of patients with subnormal spontaneous secretion of growth hormone, during the first year of treatment with growth hormone. Metabolism. 41:483-486.

44. Leger J, Carel C, Legrand I, Paulsen A, Hassan M, Czernichow P. 1994 Magnetic resonance imaging evaluation of adipose tissue and muscle tissue mass in children with growth hormone $(\mathrm{GH})$ deficiency, Turner's syndrome, and intra-uterine growth retardation during the first year of treatment with GH. J Clin Endocrinol Metab. 78:904-909.

45. Harbison MD, Gertner JM. 1990 Permissive action of growth hormone on the renal response to dietary phosphorus deprivation. J Clin Endocrinol Metab. 70:1035-1040

46. Fraser DR. 1995 Vitamin D. Lancet. 345:104-107.

47. Antoniazzi F, Radetti G, Zamboni G, Gambaro G, Adami S, Tato L. 1993 Effects of 1,25-dihydroxyvitamin D3 and growth hormone therapy on serum osteocalcin levels in children with growth hormone deficiency. Bone Miner. 21:151-156.

48. Takeuchi N, Matsumoto A, Katayama Y, et al. 1983 Changes with aging in serum lipoproteins and apolipoprotein $\mathrm{C}$ subclasses. Arch Gerontol Geriatr. 2:41-48.

49. Cuneo RC, Salomon F, Watts GF, Hesp R, Sönksen PH. 1983 Growth hormone treatment improves serum lipids and lipoproteins in adults with growth hormone deficiency. Metabolism. 42:1519-1523.

50. Kannel WB, Wilson PWF. 1992 Efficacy of lipid profiles in prediction of coronary disease. Am Heart J. 124:768-774. 